\title{
AN EXPERIMENTAL AND THEORETICAL INVESTIGATION INTO BURNING CHARACTERISTICS OF PPS-GLASS FIBER COMPOSITES
}

\author{
Arvind Atreya and Sanjay Agrawal \\ Department of Mechanical Engineering and Applied Mechanics \\ University of Michigan; Ann Arbor, MI 48109-2125
}

\begin{abstract}
In this study experiments are conducted on thick PPS-fiberglass composites instrumented with thermocouples. These samples are especially manufactured from prepreg with installed in-depth thermocouples. The samples were exposed to various external radiant heat fluxes $\left(2-7 \mathrm{~W} / \mathrm{cm}^{2}\right)$ in air and nitrogen atmospheres, and mass loss and in-depth temperatures were measured as a function of time. It was observed that the composite goes through two transformations: (1) Physical transformation from crystalline to molten PPS at about $545 \mathrm{~K}$ and (2) Chemical decomposition of molten PPS at about $813 \mathrm{~K}$. At high heat fluxes it spontaneously ignites in air. From these experiments, a melting front and a decomposition front inside the composite were identified and two models were developed and solved numerically. The first model was a simple two front (moving boundaries) model that gave excellent results for low heat fluxes i.e. prior to the onset of thermal decomposition. This model allowed us to determine the properties of the PPS-fiberglass composite prior to melting. The second model included both the melting front and the decomposition front, simulated by one-step Arrhenius decomposition kinetics. This model works satisfactorily for both low and high heat fluxes. Comparison with experiments resulted in an excellent match with in-depth temperatures and volatile mass flux rates. It was found that the properties of the composite change substantially with temperature and density. It was also determined that melting of PPS could be treated as a sudden change in density but not decomposition of PPS.
\end{abstract}

\section{INTRODUCTION}

Polymer composite materials are used in a wide variety of structural applications aboard ships and aircrafts. These materials typically consist of two phases: high strength filaments and a polymeric matrix which permeates the filaments. The filaments provide nearly all the mechanical strength while the polymer serves to protect and bond the filaments, preventing delamination. Such tailor made composites offer marked advantages over metals in mechanical strength and weight savings. However, they are subject to a significant new concern: under certain circumstances the organic polymeric binder thermally decomposes and burns. This compromises the structural integrity (which was the reason for choosing the composite) and also spreads fire from one location to the next. Unfortunately, such scenarios are not remote possibilities. Pre and post-crash aircraft fires are common and fires aboard naval ships caused by an accident or by enemy attack must be contained and not allowed to spread through the entire ship. Thus, an important issue is the knowledge of the burning characteristics of composites. As a first step, this requires quantifying the production rate of combustible gases under various external heating conditions, i.e. thermal degradation. Unfortunately, the kinetics and energetics of thermal decomposition and other physical changes such as melting and/or swelling of the composite matrix are not a priori known. Thus, separate small-scale experiments are needed to determine: (i) The decomposition kinetics. This is typically done by thermogravimetric analysis (TGA) [1]. (ii) Heat liberated or absorbed during melting or decomposition. Typically, differential thermal analysis (DTA) or differential scanning calorimetry (DSC) is used for this purpose [2]. However, data obtained from these small (thermally thin) samples can not be directly used for thick samples. Thus, models which appropriately accounts for heat and mass transfer within the sample are required. Furthermore, experiments on thick samples at different levels of external radiation are needed to determine the thermal properties, identify the reasons for the physical changes and validate the models.

Previous studies $[3,4]$ have shown that considerable expansion or contraction of the composite matrix may occur during thermal decomposition. Such dimensional changes significantly alter the heat transfer to and mass transfer from the composite matrix and must be appropriately modeled. Some successful modeling studies of thermally thick polymer composites have also been reported [5,6]. However, different composites behave differently and data and models of one composite cannot be used for another. To the best of the authors knowledge, studies on thermal degradation of PPSfiberglass composites that are often called "advanced composites" and used in aircrafts and ships, are not available in the literature.

Thus, the objectives of this work are: (i) To experimentally identify the physical and chemical processes that occur during thermal decomposition of PPS-fiberglass composites. (ii) To formulate and develop theoretical models that are capable of predicting the mass

American Institute of Aeronautics and Astronautics 
loss rate and the temperature field inside the composite. (iii) To determine the thermal properties required for the model, and (iv) To experimentally validate these models.

\section{EXPERIMENTS}

A schematic of the experimental apparatus is shown in figure 1. The top part which consists of a cone heater sits on the bottom part that houses the sample, the weighing scale and the air flow straighteners. The watercooled bottom housing is connected to a pressurized chamber which is fed by independent $\mathrm{N}_{2}$ and $\mathrm{O}_{2}$ gas lines to control the chamber atmosphere. This is essential because at high heat fluxes, the composite sample spontaneously ignites in air - changing the boundary conditions required for modeling. Once the cone heater reaches the desired heat flux (or heater element temperature), the water-cooled cover is removed to expose the composite sample. The data acquisition system is started at this time and is used to collect, store and process the voltage outputs from the weighing scale and the thermocouples. Due to small differences in the radiant heat transfer between the cone heater and the cooling plate and the cone heater and the sample, once the cooling plate is removed, a modest decrease in the heat flux is observed before approaching steady state. This transient condition was measured and represented by an exponentially decaying function, viz: $Q_{\text {rad }}=Q_{o}(1+0.31 \exp (-t / 1153.2))$, where t represents time in seconds. This expression was used for the incident heat flux in all the calculations presented in this paper.

The composite samples used in the experiments were especially fabricated from prepreg with in-laid thermocouple wires. One hundred sheets $(15.25 \mathrm{~cm} x$ $15.25 \mathrm{~cm}$ ) of Avtel PPS composite tape (manufactured by Phillips 66 company) were used to obtain a final sample thickness of $17.7 \mathrm{~mm}$. The prepreg tape had 32\% PPS (polyphenylene sulfide, PR10X-2) and 68\% glass fibers (E-glass) by weight (PPS resin volume was $47 \%$ and glass fiber volume was $53 \%$ ). Sixteen thermocouples were inlaid between the 100 sheets with 2 thermocouples (laterally $1.27 \mathrm{~cm}$ apart) on both the top and the bottom layers and 2 thermocouples after 2, 6, 14, 24, 49 and 89th layers. The sample was then assembled in a stainless steel picture frame with a stainless steel base by using 100 prepreg sheets with thermocouples (alternate sheets had perpendicular fiber orientation). A $1.27 \mathrm{~cm}$ thick aluminum block that fit in the picture frame was used to cover the top of the sample. The sample in the picture frame was then subjected to elevated pressure and temperature in a heated press. The temperature and pressure histories during the sample fabrication process are shown in figure 2. It was first pressurized to 800 psig for 5 minutes at room temperature to release any trapped air between the sheets. Pressure was then reduced to 25 psig and the temperatures of both the top and the bottom surfaces of the press were slowly increased to $350{ }^{\circ} \mathrm{C}$ in 50 minutes. The temperature and pressure were then held constant for another 30 minutes to allow the resin to melt throughout the sample. Finally, to force the molten PPS resin between the fibers, the pressure was increased to 100 psig for about 5 minutes while keeping the temperature constant. The sample was then cooled to ambient temperature at 25 psig. This procedure was determined by hit-and-trial and by monitoring the indepth temperatures. By cutting a finished sample in the center, it was confirmed that this procedure yielded excellent results without layer delamination and with proper installation of the thermocouple wires.

The above procedure of installing the thermocouples is unique and different from previous investigations, where typically holes were drilled in the composite to place the thermocouples [5]. In the present case, the thermocouple locations were precisely known prior to sample fabrication and new thermocouple locations after sample fabrication were calculated from the final sample thickness and the number of prepreg sheets placed on top of a given thermocouple. However, it is important to check the thermocouple locations because they may have changed during the fabrication process. To check them low-temperature steady-state heat conduction experiments were performed on the sample. The sample was placed between two $2.54 \mathrm{~cm}$ thick aluminum sheets to ensure uniform heat distribution. The top surface was maintained at a constant temperature $\left(80^{\circ} \mathrm{C}\right)$ while the bottom surface was kept at ambient temperature $\left(20^{\circ} \mathrm{C}\right)$. The measured steady state temperatures inside the sample were plotted against the calculated thermocouple locations. An excellent straight line fit confirmed that the thermocouple locations were not altered during the fabrication process. These thermocouple locations were: \#1 - top surface; \#2 - $0.35 \mathrm{~mm}$ from the top surface; \#3 $1.06 \mathrm{~mm}$; \#4 - $2.48 \mathrm{~mm}$; \#5 - $4.25 \mathrm{~mm}$; \#6 - $8.67 \mathrm{~mm}$; \#7 - $15.75 \mathrm{~mm}$ and \#8 - bottom surface. Also two thermocouples, $1.27 \mathrm{~cm}$ laterally apart, were placed at each location. In all the figures described in the subsequent sections, the numbers correspond to the above thermocouple locations.

\section{EXPERIMENTAL RESULTS}

\section{Thermal Decomposition Experiments in Air and $\mathrm{N}_{2}$}

The composite samples were first tested in air at 2, 3.5, 5, 6 and $7 \mathrm{~W}^{\mathrm{cm}} \mathrm{cm}^{2}$ external radiation. [Note: For reasons explained earlier, external radiation of $2 \mathrm{~W} / \mathrm{cm}^{2}$ implies that the actual heat flux on the sample surface was: $Q_{\text {rad }}=2(1+0.31 \exp (-t / 1153.2)) \mathrm{W} / \mathrm{cm}^{2}$. This value was used in model calculations.] For experiments in air, at high heat fluxes $\left(5 \mathrm{~W} / \mathrm{cm}^{2}\right.$ and above) the sample spontaneously ignited (spontaneous ignition temperature of PPS is about $813 \mathrm{~K}$ ), making the externally applied heat 
flux unknown due to additional heat from the flame. Figure 3 shows the in-depth temperature measurements for the case of $5 \mathrm{~W} / \mathrm{cm}^{2}$ in air. The sample spontaneously ignited at about $300 \mathrm{sec}$ as marked by the jump in the temperatures near the top surface. Quantifying the heat flux required for this jump is difficult and it makes the comparisons between the models and the experiments also difficult. To overcome this difficulty experiments were conducted in nitrogen atmosphere. Figure 4 shows the measured in-depth temperatures in air and $\mathrm{N}_{2}$ atmospheres for $2 \mathrm{~W} / \mathrm{cm}^{2}$ external radiation. Clearly, the in-depth temperatures are different in the two atmospheres even without spontaneous ignition. Similar results were obtained by Kashiwagi [7] where the presence of oxygen was found to change the decomposition chemistry. Since fires are primarily diffusion flames, there is negligible $\mathrm{O}_{2}$ on the fuel side. Thus, thermal decomposition of the composite, in the presence of a diffusion flame is likely to occur in the absence of oxygen. Hence, experiments conducted in $\mathrm{N}_{2}$ (or an inert atmosphere) are expected to provide reliable fuel mass production rates under fire conditions.

In these experiments it was observed that the composite undergoes two transformations: (i) A physical transformation from crystalline to molten PPS at $545 \mathrm{~K}$, and (ii) Chemical decomposition of molten PPS which occurs vigorously around $813 \mathrm{~K}$. As seen from the plateaus in figures 3 and 4 , these transformations have a noticeable effect on the measured in-depth temperatures. Hence, theoretical models must consider the energy required by these transformations and the resulting changes in the thermophysical properties. It is important to note that the most difficult part of developing a model is to independently determine the values of these thermophysical properties.

Experimental observations also show that blistering occurs on the top surface which eventually subsides with the volatiles tearing through the glass fibers. This clearly indicates internal pressure generation. It is believed that the steps observed in the mass loss data (as seen in figure 5 ) are caused by this pressure generation and relief cycle. While pressure significantly affects the initial mass evolution rate, it is not expected to play an important role in the energy balance except through changes in the physical properties of the sample. Including pressure generation in the theoretical model requires the knowledge of porosity and its changes during thermal decomposition. Since, these changes are unknown and difficult to quantify, pressure generation has been neglected in the present generation theoretical models. Swelling of the matrix, however, changes the thermal conductivity. Thermal conductivity near the surface, which dictates the heat flow to the lower region, decreases sharply. This contributes to the sharp rise in the temperatures near the surface. As seen in figure 4, thermocouples \#2 \& \#3 show such a sharp rise around $545 \mathrm{~K}$. While vigorous thermal decomposition of the composite is expected to occur around $813 \mathrm{~K}$ (spontaneous ignition temperature), sufficient volatiles are formed after melting (at $545 \mathrm{~K}$ ) to begin delamination of the top layers.

The effect of delamination is clearly evident in figure 3 , where temperatures measured by both laterally placed thermocouples at each locations are plotted. Locations \#2 and \#4 from the top surface show the greatest difference. Hence they are highlighted by connecting the data points with the regression lines. Locations \#1 \& \#3 did not show a substantial difference either because the entrapped gasses easily ruptured the glass fibers on the top surface or because the local delamination was laterally removed from the thermocouple location. Locations \#5, \#6, \#7 \& \#8 do not show any difference probably because delamination did not occur due to lower temperatures and more deeply embedded thermocouples. However, whenever delamination and subsequent swelling occurred in the neighborhood of the thermocouple, substantial temperature differences were recorded. For example, at location \#2 the maximum temperature difference between the two laterally displaced thermocouples $(1.27 \mathrm{~cm}$ apart) is nearly $150^{\circ} \mathrm{C}$, while at $\# 4$ this difference is almost $100^{\circ} \mathrm{C}$. Note that melting of the PPS resin and subsequent gassification are essential conditions for layer delamination to occur. Thus, temperatures measured by the two thermocouples (\#2 \& \#4 in figure 3) are identical in the initial period, i.e. prior to melting at about $545 \mathrm{~K}$.

Implications of these results for theoretical models are that both the heat required for melting and the decrease in the effective thermal conductivity after melting due to delamination must be included in the models. Without including these effects, the sharp rise in the temperatures after melting (as observed in figures 3 \& 4) cannot be reproduced. Figures 3 and 5 also indicate that the temperatures and the decomposition rates are higher in air than in nitrogen. However, the character of the curves are similar. Thus, while different constants for decomposition kinetics and energetics may be required for the two atmospheres, the basic structure of the model remains unchanged.

\section{Determination of Properties:}

To develop a predictive model of the above phenomena, it is necessary to independently determine the properties. These include: thermal conductivity and its changes with melting and decomposition, specific heat, emissivity, heat transfer coefficients, heat of melting, heat of decomposition and kinetic parameters for melting and thermal decomposition. Determination of these properties is described below. 
Decomposition of PPS: To obtain the degradation characteristics of PPS, high resolution TGA experiments with $50^{\circ} \mathrm{C} / \mathrm{min}$ heating rate were performed in nitrogen on a $34 \mathrm{mg}$ sample. Typical results of these experiments are presented in figure 6 . Only $62.5 \%$ of the available PPS decomposed until $1000^{\circ} \mathrm{C}$. Thus, $12 \%$ of the total composite weight (or $37.5 \%$ of PPS) remained in the composite matrix as PPS char. This information was used in the theoretical model. The use of TGA and DSC results to obtain the kinetic parameters is discussed along with the model formulation.

Specific Heat and Heats of Melting and Decomposition: Two types of DSC experiments were conducted for determining the specific heat of the composite. These results are plotted in figure 7 . In the first, pure PPS resin sample was used and the specific heat of the composite was obtained by a mass weighted average of the measured PPS specific heat and the published E-fiber glass data [9]. In the second method, a small composite sample $(\sim 13 \mathrm{mg})$ was used to determine the combined specific heat. As shown in figure 7 , both methods give nearly identical results. For temperatures higher than $545 \mathrm{~K}$ results are not useful due to melting of PPS. However, Ref [10] has shown that specific heat of PPS near or below its melting point is a weak function of temperature. Thus specific heat of the composite (i.e. PPS melt and glass fiber) was assumed to be constant after $545 \mathrm{~K}$. This is not expected to cause significant error because PPS is only $32 \%$ by weight of the composite and the specific heat of glass changes by less than $4 \%$ in the $300-600^{\circ} \mathrm{C}$ temperature range. The values used in the model are also plotted in figure 7 and are given by: $\mathrm{C}_{\mathrm{p}}=$ $822+1.1 \mathrm{~T}$ for $\mathrm{T}<272{ }^{\circ} \mathrm{C}$; and $\mathrm{C}_{\mathrm{p}}=1120 \mathrm{~J} / \mathrm{kgK}$ for $\mathrm{T} \geq$ $272^{\circ} \mathrm{C}$. The DSC experiments were also used to determine the heat of melting. As shown in figure 7, the heat of melting was found to be $70 \mathrm{~kJ} / \mathrm{kg}$ of PPS.

The heat of decomposition could not be determined from the DSC experiments because of high temperatures. Hence, DTA experiments were conducted using a constant heating rate of $5^{\circ} \mathrm{C} / \mathrm{min}$ (same as that used in the DSC experiments). Since DTA results are qualitative, a ratio of the areas corresponding to the endothermic heats of melting and decomposition was calculated. Using this ratio and the known value for the heat of melting, the heat of decomposition was estimated to be: $180 \mathrm{~kJ} / \mathrm{kg}$ of PPS.

Thermal Conductivity and other Heat Transfer Properties: Separate experiments were conducted to determine the temperature dependent thermal conductivity. The sample was subjected to a nondestructive low heat flux of $0.6 \mathrm{~W} / \mathrm{cm}^{2}$ and temperatures and mass loss were measured as a function of time. This low heat flux kept the surface temperature significantly below the melting point of PPS. Mass loss measurements confirm that thermal decomposition did not occur during these low heat flux experiments. As seen from the results of two experiments plotted in figure 8 , these experiments were very repeatable from sample to sample. The measured temperature profiles along with the specific heat and measured density of the sample $\left(2400 \mathrm{~kg} / \mathrm{m}^{3}\right)$ were used to determine the thermal conductivity of the composite by a parameter estimation technique [11]. Thermal conductivity was found to be well represented by the expression $k=0.434+0.301 \times 10^{-3} \mathrm{~T}$ in the $0-160^{\circ} \mathrm{C}$ temperature range.

To determine the thermal conductivity via the parameter estimation technique, surface emissivities and convective heat transfer coefficients are also needed. The natural convection coefficients at the top and the bottom surfaces were obtained from the published results [12]. Now, using the known heat flux, measured temperature profiles, material properties and natural convection coefficients, emissivities of the top and bottom surfaces were found by a simple energy balance. The procedure for determining the thermal conductivities and emissivities was iterated until a satisfactory match with the measured temperature profiles was obtained. As shown in figure 8 , good agreement between the calculated and measured temperatures was obtained. This suggests that the properties were correctly determined for the temperature range of the low heat flux experiment.

Further Experiments in Nitrogen: Once the samples used in the low heat flux $\left(0.6 \mathrm{~W} / \mathrm{cm}^{2}\right)$ experiments had cooled to room temperature, they were re-exposed to a radiant heat flux of $2 \mathrm{~W} / \mathrm{cm}^{2}$. At this heat flux significant mass loss did not occur and the sample was only partially decomposed. The measured in-depth temperatures for this case are plotted in figure 9. As noted earlier, the properties are different in the melted and partially decomposed zone due to delamination. To estimate these properties, the partially decomposed sample was again exposed to $0.6 \mathrm{~W} / \mathrm{cm}^{2}$ radiant heat flux after it had cooled to ambient temperature. The reduced thermal conductivity in the upper region of the sample was determined by using the top three measured temperatures and the parameter estimation technique [11]. The estimated value was $0.15 \mathrm{~W} / \mathrm{mK}$. This average value was used in the theoretical calculations as the thermal conductivity of the region containing molten PPS and glass fiber, i.e. for $813 \mathrm{~K}>\mathrm{T} \geq 545 \mathrm{~K}$. Also, as per figure $7, \mathrm{C}_{\mathrm{ps}}$ and $\rho$ were also assumed constant in this region. The measured temperature profiles in the bottom half of the sample during the $0.6 \mathrm{~W} / \mathrm{cm}^{2}$ experiment were used to estimate the average thermal conductivity in the unmelted region, i.e. $\mathrm{T}<545 \mathrm{~K}$. It was found to be $0.48 \mathrm{~W} / \mathrm{mK}$. As expected, this value is close to the previous estimate because the bottom half of the sample did not melt during the $2 \mathrm{~W} / \mathrm{cm}^{2}$ experiment. As seen in figure 9, calculations using the estimated property values compare favorably 
with the experiments. It is important to emphasize that the properties used in these calculations were determined by separate low heat flux experiments.

Form the comparison presented in figure 9, it is clear that despite determining the thermal properties before and after the $2 \mathrm{~W} / \mathrm{cm}^{2}$ experiment via additional nondestructive experiments at $0.6 \mathrm{~W} / \mathrm{cm}^{2}$ and inverse heat transfer calculations, the theory (to be described later) was unable to completely capture the humps in the measured temperature profiles. It is suspected that these are caused by blistering of the top surface which subsided after some time. As stated earlier, surface blistering (or expansion) was not included in the model calculations because changes in porosity of the composite matrix during thermal decomposition could not be quantified. However, to test the hypothesis that humps are due to blistering of the composite matrix, the sample which was exposed to $0.6 ; 2.0 ; 0.6 \mathrm{~W} / \mathrm{cm}^{2}$ cycle was re-exposed to 2 $\mathrm{W} / \mathrm{cm}^{2}$. Upon re-exposing blistering did not occur because of the already established volatile escape paths. Thus, temperature humps are not expected and a better comparison between the model calculations and the experiment is anticipated. The measured and calculated in-depth temperature profiles for this case are plotted in figure 10. Clearly, the behavior of the composite is different. The humps in the temperature profiles, observed in figures 4 and 9 after the melting of PPS, have disappeared and a better comparison with the model is evident. Figure 10 also confirms that the properties were correctly determined.

As stated earlier, $2 \mathrm{~W} / \mathrm{cm}^{2}$ exposure barely begins to decompose the sample and higher heat fluxes are required to generate sufficient mass loss to support a diffusion flame. Thus, further experiments on new samples were conducted at 3.5 and $5 \mathrm{~W} / \mathrm{cm}^{2}$ heat fluxes. As before, these samples were also exposed to a non-destructive low heat flux $\left(0.6 \mathrm{~W} / \mathrm{cm}^{2}\right)$ both before and after the high heat flux exposure to obtain the properties. The results of high heat flux experiments are presented in figures 5, 11 and 12. As seen from figure 5, substantial decomposition occurred at $5 \mathrm{~W} / \mathrm{cm}^{2}$ and only glass fibers and PPS char residue remained in the zone $T>813 \mathrm{~K}$. The thermal properties of this zone are different from those determined earlier. The average thermal conductivity of this zone was again obtained from subsequent low heat flux $\left(0.6 \mathrm{~W} / \mathrm{cm}^{2}\right)$ experiments using the top three thermocouples. It was found to be $0.3 \mathrm{~W} / \mathrm{mK}$. This is higher than $0.15 \mathrm{~W} / \mathrm{mK}$ obtained for the zone $813 K>T \geq 545 K$, because of interstitial radiation through the glass fibers.

\section{MODEL DEVELOPMENT}

The objective of the model is to predict the mass loss rate of the composite when exposed to fire-level heat fluxes. This requires modeling the melting and decomposition processes occurring during the experiments. These were modeled by: (i) using two sharp moving boundaries corresponding to melting and decomposition fronts, and (ii) using temperature dependent distributed melting and decomposition zones that were assumed to follow the Arrhenius temperature dependence. These models are described below.

\section{The Two Front Model}

In the two front model it is assumed that a melting front $s_{m}(t)$ travels through the solid and the solid composite density, $\rho_{s}$, changes abruptly to the melt composite density, $\rho_{m}$, at a known fixed melting temperature, $T_{m}$. Following the melting front, a decomposition front $s_{v}(t)$ travels through the solid and $\rho_{m}$ changes abruptly to $\rho_{v}$ (note that $\rho_{v}=\rho_{\text {glass }}+$ density of PPS char residue) at a known fixed degradation temperature, $T_{v}$. The schematic of this process is shown in the inset in figure 1. At any instant, the region $0<x<$ $s_{v}(t)$ consists of glass fibers and PPS char residue, the region $s_{v}(t)<x<s_{m}(t)$ consists of molten PPS and glass fibers, and the region $s_{m}(t)<x<l$ consists of solid PPS and glass fibers. Where ' $l$ ' is the sample thickness. The governing equations in these zones are [13]:

$k_{v} \frac{\partial^{2} T}{\partial x^{2}}=\rho_{v} C_{p v} \frac{\partial T}{\partial t}, \quad 0<x<s_{v}(t)$

Here, the subscript ' $S$ ' represents the properties of solid PPS and glass fiber composite, ' $m$ ' represents the properties of molten PPS and glass fiber composite and

$$
\begin{aligned}
& k_{m} \frac{\partial^{2} T}{\partial x^{2}}=\rho_{m} C_{p m} \frac{\partial T}{\partial t}, \quad s_{v}(t)<x<s_{m}(t) \\
& k_{s} \frac{\partial^{2} T}{\partial x^{2}}=\rho_{s} C_{p s} \frac{\partial T}{\partial t}, \quad s_{m}(t)<x<l
\end{aligned}
$$

' $v^{\prime}$ represents the properties of PPS char residue and glass fiber composite. The boundary conditions at the top and the bottom surfaces are:

$$
\begin{aligned}
& -k_{v}\left(\frac{\partial T}{\partial x}\right)_{x=0}=Q_{r a d}-\varepsilon_{s} \sigma\left(T_{s}^{4}-T_{\infty}^{4}\right)-h_{s}\left(T_{s}-T_{\infty}\right) ; \\
& -k_{s}\left(\frac{\partial T}{\partial x}\right)_{x=l}=-\varepsilon_{b} \sigma\left(T_{b}^{4}-T_{\infty}^{4}\right)-h_{b}\left(T_{b}-T_{\infty}\right)
\end{aligned}
$$

The interface conditions at the decomposition front $s_{v}(t)$ are:

$$
\begin{aligned}
& T\left(S_{v}(t), t\right)_{\text {melt zone }}=T\left(S_{v}(t), t\right)_{\text {decomp. zone }}=T_{v} ; \\
& k_{m}\left(\frac{\partial T}{\partial x}\right)_{S_{v}(t)}-k_{v}\left(\frac{\partial T}{\partial x}\right)_{S_{v}(t)}=\left(\rho_{m}-\rho_{v}\right) Q_{m} \frac{d S_{v}(t)}{d t}
\end{aligned}
$$

where $Q_{m}$ is the endothermic heat of decomposition of molten PPS. 
The interface conditions at the melt front $s_{m}(t)$ are:

$$
\begin{aligned}
& T\left(S_{m}(t), t\right)_{\text {solid zone }}=T\left(S_{m}(t), t\right)_{\text {melt zone }}=T_{m} \text {. (8) } \\
& k_{S}\left(\frac{\partial T}{\partial x}\right)_{S_{m}(t)}-k_{m}\left(\frac{\partial T}{\partial x}\right)_{S_{m}(t)}=\left(\rho_{s}-\rho_{\text {glass }}\right) Q_{S} \frac{d S_{m}(t)}{d t}(9)
\end{aligned}
$$

where $Q_{s}$ is the endothermic heat of melting. For surface temperatures lower than $T_{m}$, only Eqn. (3) is solved using the boundary conditions (4) and (5). For surface temperatures lower than the vaporization temperature ' $\mathrm{T}_{\mathrm{v}}$ ', Eqns. (2) and (3) are solved using the boundary conditions (4), (5), (8) and (9). Special convergence schemes are required for handling sharp changes in the property values at the front locations. This numerical scheme is described in greater detail in Refs. [14,15]. For the computations presented here, constant average properties in each zone were used. These are tabulated in Table 1. Figures 9 through 12 present a comparison of the numerically calculated temperatures with the experimental measurements. The surprisingly good agreement confirms that the melting and decomposition processes may be approximated as two sharp moving fronts as long as the properties in the resulting three zones are well known. However, the mass loss, presented in figure 5, does not compare equally well. This suggests that decomposition of molten PPS (which is responsible for the mass loss) may not be appropriately represented by a sharp moving front. Thus, a model with Arrhenius decomposition kinetics was developed. This is presented below.

\section{The Decomposition Model}

In this model, instead of assuming step changes in density and other property values across the zonal boundaries, melting and decomposition is assumed to occur in a temperature dependent manner. Thermal decomposition is known to be a temperature dependent process, and as seen from the DSC experiments (figure 7), melting is also not a sharp transition. Thus, both melting and decomposition were assumed to follow Arrhenius type of temperature dependence. Consistent with this assumption, properties were also assumed to vary smoothly and were taken as functions of both density and temperature. The resulting governing equations are [16]:

Energy:

$$
\begin{aligned}
& \rho(T) C_{p}(T) \frac{\partial T}{\partial t}=\frac{\partial}{\partial x}\left(k \frac{\partial T}{\partial x}\right)+\left(M_{g} C_{p g}\right) \frac{\partial T}{\partial x}-\left(\frac{\partial \rho_{p p s, s}}{\partial t}\right) \times \\
& \times\left(Q_{s}+H_{s}-H_{m}\right)-\left(\frac{\partial \rho_{p p s, m}}{\partial t}+\frac{\partial \rho_{p p s, s}}{\partial t}\right)\left(Q_{m}+H_{m}-H_{v}\right)
\end{aligned}
$$

Where: $H=\int_{T_{\infty}}^{T} C p(T) d T$
Mass: $\quad \frac{\partial M_{g}}{\partial x}=\frac{\partial \rho_{p p s, m}}{\partial t}+\frac{\partial \rho_{p p s, s}}{\partial t}$

The first term in Eq. (10) represents the rate of change of stored energy, the second term represents the energy conducted and the subsequent terms represent: the energy carried away by the evolved gases, the energy consumed in melting solid PPS and the energy used in decomposing the molten PPS. Expansion and shrinkage of the composite are neglected. In equations (10) and (11), properties without subscripts represent the values for the composite. The subscript pps,s corresponds to solid PPS and pps, $m$ corresponds to molten PPS. For e.g., $\rho_{p p s, s}$ and $\rho_{p p s, m}$ are the solid and molten PPS densities respectively. Also, $M_{g}=\rho_{g} U_{g}$ is the mass flux at any location $x$ and $M_{g}=0$ corresponds to no decomposition.

Melting of PPS represents the disappearance of solid PPS which is expressed by the following Arrhenius equation:

$$
\frac{\partial \rho_{p p s, s}}{\partial t}=-A_{S} \rho_{p p s, s} e^{-E_{S} / R T}
$$

Decomposition of PPS represents the disappearance of molten PPS which is represented by:

$$
\frac{\partial \rho_{p p s, m}}{\partial t}=-\frac{\partial \rho_{p p s, s}}{\partial t}-A_{m}\left(\rho_{p p s, m}-\rho_{p p s, \text { char }}\right) e^{-E_{m} / R T}
$$

Where, $\rho_{p p s, \text { char }}$ is the density of left over PPS char residue (determined from TGA experiments). The top and bottom boundary conditions are the same as those described by Eqns. (4) and (5). The thermal conductivity is assumed to vary smoothly with density and temperature according to the equation:

$$
k=k_{p p s, s} \frac{\rho_{p p s, s}}{\rho_{s}}+k_{p p s, m} \frac{\rho_{p p s, m}}{\rho_{s}}+k_{\text {glass }} \frac{\rho_{\text {glass }}}{\rho_{s}} ; k=k_{o}+k_{l} T
$$

As described earlier, thermal conductivity changes substantially with melting and decomposition. It was experimentally determined by nondestructive low heat flux experiments conducted before and after the primary experiment. The experimentally determined values were: (i) For the virgin composite $k=0.434+0.301 \times 10^{-3} \mathrm{~T}$ $\mathrm{W} / \mathrm{mK}$, which is valid up to $160^{\circ} \mathrm{C}$; (ii) For the molten PPS zone only an average value could be determined from the samples remaining after the primary experiment. This is because the low heat flux experiments were designed not to reach the melt temperature. The average value in the melt zone was found to be $k=0.15 \mathrm{~W} / \mathrm{mK}$; (iii) Likewise, the average value in the decomposed zone was $k=0.3 \mathrm{~W} / \mathrm{mK}$. Using these measured values, the following expression for thermal conductivity at various temperatures and densities was determined: 


$$
k=0.3+0.563 \frac{\rho_{p p s, s}}{\rho_{s}} 0.469 \frac{\rho_{p p s, m}}{\rho_{s}} ;\left(\frac{W}{m K}\right)
$$

The Arrhenius constants needed for describing the disappearance of solid PPS ( $A_{s}$ and $E_{s}$ in Equ. 12) were obtained from the DSC curve shown in figure 7 . The TGA results (figure 6) could not be used for determining the Arrhenius constants in Equ. (13) because it includes the density changes during melting. Thus, $E_{m}$ was assumed to be the same as that used for melting and $A_{m}$ was obtained by matching the measured mass flux data for one of the experiment. The constant values used in the model are given in Table 2.

Numerical solution of Eqns. (10) through (13) was obtained by using the Crank-Nicolson method. These computations were significantly faster than the two front model. Further details regarding the numerical solution procedures may be found in Ref. [16]. The results of this comprehensive model are also plotted in figures 9 through 12 for various heat fluxes. For lower heat fluxes (figure 9 and 11), the model predictions are very close to the predictions of the two front model and the data. For higher heat fluxes (figure 12), the measured temperatures compare favorably at early times, but at later times the temperatures in the upper region of the sample do not agree with the calculations. The reason for this disagreement is that once the PPS has volatilized, the glass fibers recede; i.e. the fiberglass matrix shrinks. This changes both the thermocouple locations and the sample thermal conductivity. Since, sample shrinkage and expansion were not included in either of the models, a better comparisons could not be obtained. The mass loss results (figure 5) also compare favorably with the data. However, a better choice of Arrhenius constants (in Eqn. 13) and a better method of their determination are needed.

\section{CONCLUSIONS}

In this study, results of thermal decomposition experiments conducted on PPS-fiberglass composites are presented. These composite samples were exposed to different heat fluxes in air and $\mathrm{N}_{2}$ environments. It was found that PPS melts around $545 \mathrm{~K}$ and decomposes around $813 \mathrm{~K}$. This gives rise to two fronts traveling through the composite sample during decomposition. Two models of this process were developed: (i) A two front model that assumes discontinuous changes, and (ii) An Arrhenius kinetics model. The property values used in these models were determined by separate experiments using low heat flux exposures and TGA, DSC and DTA tests. Favorable comparisons with the data were obtained indicating that melting and decomposition processes were successfully modeled. At lower heat fluxes the constant property front model and the variable property decomposition model predict nearly identical results. However, further improvements in the models are needed for higher heat fluxes. These improvements are: (i) including expansion and shrinkage of the composite matrix, and (ii) a better method for determining the decomposition constants. From the numerical calculations it is apparent that the decomposition process is better modeled by an Arrhenius type expression since the density changes occurs gradually. The melting process, however, may be modeled by either method because the transformations are comparably sharper. Finally, special attention was devoted toward determining the thermophysical properties because they change drastically with the transformations of the composite matrix.

\section{REFERENCES}

1. Schneider, H.A., "Thermogravimetric kinetics of polymer degradation: Science of fiction?", Polymer Engineering and Science, V. 32., p. 1309, (1992).

2. Henderson, J.B., Wiebelt, J.A. and Tant, M.R., "A method for the determination of the specific heat and heat of decomposition of composite materials", Thermochimica Acta, v. 57, p. 161, (1982).

3. Tant, M.R., Henderson, J.B. and Boyer, C.T., "Measurement and modeling of the thermochemical expansion of polymer composites", Composites, v. 16, No. 2, (1985).

4. Boyer, G.T. and Thomas, W.C., "An Analytical Investigation of Charring composite undergoing thermochemical expansion", ASME paper No. 85-HT-54, National Heat Transfer Conference, (1985).

5. Henderson, J.B., Wiebelt, J.A. and Tant, M.R., "A model for the thermal response of polymer composite materials with experimental verification", Journal of Composite Materials, V. 19, p. 579, (1985).

6. Brown, J.E., Loftus, J.J. and Dipert, R.A., "Fire characteristics of composite materials - A review of literature", NBSIR 85-3226, NBS, (1985).

7. Kashiwagi, T. and Ohlemiller, T. J., "A Study of Oxygen Effects on Nonflaming Transient Gasification of PMMA and PE during Thermal Irradiation," 19th Symposium (International) on Combustion, The Combustion Institute, p. $815,(1982)$.

8. Agrawal, S., Atreya, A., and Mekki, K. "Burning characteristics of composite materials", Proceedings of the Central Section of the Combustion Institute, April (1991).

9. Engineered Materials Handbook, vol. 1 Composites, ASM International, Metal Park, Ohio, USA, (1987).

10. Menczel, J.D. and Collins, G.L., "Thermal analysis of poly(phenylene sulfide) polymers. I: Thermal characterization of PPS polymers of different molecular weights", Polymer Engineering and Science, vol. 32, p. 1264, (1992).

11. Beck, J.V. and Arnold. K.J., Parameter estimation in engineering and science, John Wiley and Sons, Inc., (1977)

12. Lloyd, J.R. and Moran, W.R., ASME Paper 74-WA/HT-66, (1974).

13. Ozisik, M.N., Heat Conduction, John Wiley and Sons, Inc., (1980).

14. Nurbakhsh, $\mathrm{S}, \mathrm{PhD}$ thesis, Michigan State University, East Lansing, MI, (1989). 
15. Ehrlich, L.W., "A numerical method of solving a heat flow problem with moving boundaries", JACM, vol. 5(2), p. 161, (1958).

Table 1\&2: Property Values used in Front \& Decomposition Models

\begin{tabular}{|c|c|c|c|}
\hline Property & Front Model & Property & $\begin{array}{l}\text { Decomposition } \\
\text { Model }\end{array}$ \\
\hline $\begin{array}{l}\rho_{\mathrm{s}}\left(\mathrm{kg} / \mathrm{m}^{3}\right) \\
\rho_{\mathrm{m}} \\
\rho_{\mathrm{v}}\left(\rho_{\text {glass }}\right)\end{array}$ & $\begin{array}{l}2400 \\
2400 \\
1936(1632)\end{array}$ & $\begin{array}{l}\rho(\mathrm{T}) \\
\left(\mathrm{kg} / \mathrm{m}^{3}\right)\end{array}$ & $\rho_{\text {glass }}+\rho_{\mathrm{pps}, \mathrm{s}}+\rho_{\mathrm{pps}, \mathrm{m}}$ \\
\hline $\begin{array}{l}\mathrm{C}_{\mathrm{ps}}(\mathrm{J} / \mathrm{kgK}) \\
\mathrm{C}_{\mathrm{pm}} \\
\mathrm{C}_{\mathrm{pv}}\end{array}$ & $\begin{array}{l}990, \mathrm{~T}<\mathrm{T}_{\mathrm{m}} \\
1120, \mathrm{~T}>\mathrm{T}_{\mathrm{m}} \\
1120, \mathrm{~T}>\mathrm{T}_{\mathrm{v}}\end{array}$ & $\begin{array}{l}\mathrm{C}_{\mathrm{p}} \\
(\mathrm{J} / \mathrm{kgK})\end{array}$ & $\begin{array}{l}1.1 \mathrm{~T}+822, \mathrm{~T}<272 \mathrm{C} \\
1120, \quad \mathrm{~T}>272 \mathrm{C}\end{array}$ \\
\hline $\begin{array}{l}\mathrm{k}_{\mathrm{ps}} \\
\mathrm{k}_{\mathrm{pm}}(\mathrm{W} / \mathrm{mK}) \\
\mathrm{k}_{\mathrm{pv}}\end{array}$ & $\begin{array}{l}0.48, \mathrm{~T}<\mathrm{T}_{\mathrm{m}} \\
0.15, \mathrm{~T}>\mathrm{T}_{\mathrm{m}} \\
0.30, \mathrm{~T}>\mathrm{T}_{\mathrm{v}}\end{array}$ & $\begin{array}{l}\mathrm{C}_{\mathrm{p}, \text { gas }} \\
(\mathrm{J} / \mathrm{kgK})\end{array}$ & 1060 \\
\hline $\begin{array}{l}\mathrm{Q}_{\mathrm{s}}(\mathrm{kJ} / \mathrm{kg}) \\
\mathrm{Q}_{\mathrm{m}}(\mathrm{kJ} / \mathrm{kg})\end{array}$ & $\begin{array}{l}70 \\
180\end{array}$ & $\mathrm{k}(\mathrm{W} / \mathrm{mK})$ & $\begin{array}{l}0.3+0.5625 \rho_{\mathrm{pps}, \mathrm{s}} / \rho_{\mathrm{s}} \\
-0.46875 \rho_{\mathrm{pps}, \mathrm{m}} / \rho_{\mathrm{s}}\end{array}$ \\
\hline $\begin{array}{l}\mathrm{T}_{\mathrm{m}} \\
\mathrm{T}_{\mathrm{v}}\end{array}$ & $\begin{array}{l}545 \mathrm{~K}(272 \mathrm{C}) \\
813 \mathrm{~K}(541 \mathrm{C})\end{array}$ & $\begin{array}{l}\mathrm{Q}_{\mathrm{s}}(\mathrm{kJ} / \mathrm{kg}) \\
\mathrm{Q}_{\mathrm{m}}(\mathrm{kJ} / \mathrm{kg})\end{array}$ & $\begin{array}{l}70 \text { (endothermic) } \\
180 \text { (endothermic) }\end{array}$ \\
\hline $\begin{array}{l}\mathrm{h}_{\mathrm{f}}, \mathrm{h}_{\mathrm{b}} \\
\left(\mathrm{W} / \mathrm{m}^{2} \mathrm{~K}\right) \\
\varepsilon_{\mathrm{f}}, \varepsilon_{\mathrm{b}}\end{array}$ & $\begin{array}{l}10,5 \\
0.7,0.7\end{array}$ & $\begin{array}{l}E_{s} / R(K) \\
E_{m} / R(K)\end{array}$ & $\begin{array}{l}22000 \\
22000\end{array}$ \\
\hline $1(\mathrm{~m})$ & 0.0177 & $\begin{array}{l}A_{s} \\
A_{m}\end{array}$ & $\begin{array}{l}4.5 \times 10^{14} \\
3.0 \times 10^{9}\end{array}$ \\
\hline
\end{tabular}

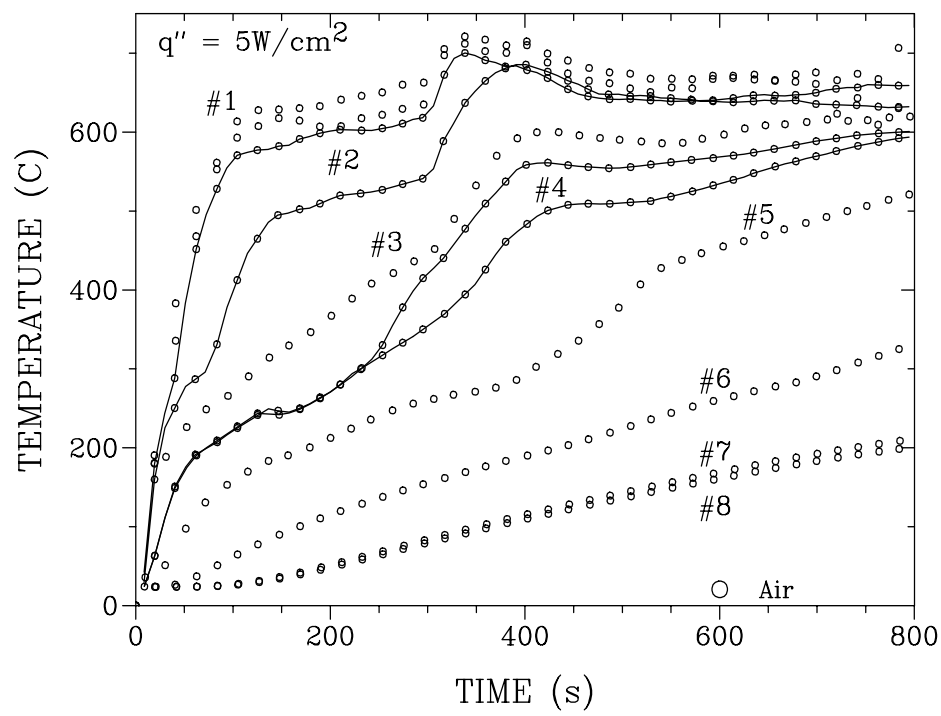

Figure 3: In-depth temperature profiles for $5 \mathrm{~W} / \mathrm{cm}^{2}$ in air. Thermocouple Locations: \#1 -top surface; \#2 - $0.35 \mathrm{~mm}$ below the top; \#3 - 1.06 mm; \#4 - 2.48 mm; \#5 - 4.25 mm; \#6 -8.67 $\mathrm{mm} ; \# \mathbf{7}$ - 15.75 and $\# \mathbf{8}$ - bottom surface. Note: There are two thermocouples at each location laterally $1.27 \mathrm{~cm}$ apart. \#2 and \#4 are emphasized by regression lines.
16. Atreya, A., PhD Thesis, Harvard University, Cambridge, MA, (1983)

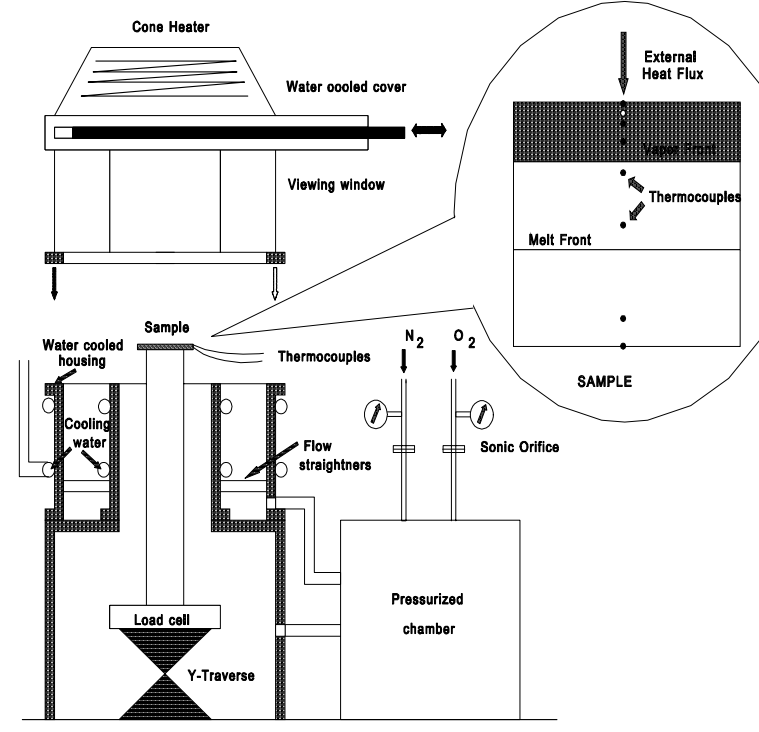

Figure 1: A schematic of the experimental apparatus. The inset shows an enlarged view of the sample with thermocouples.

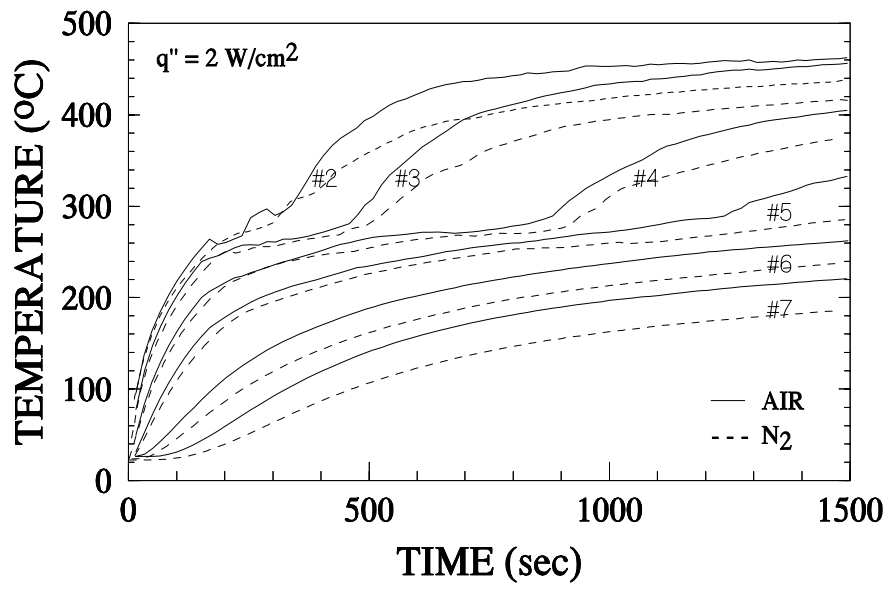

Figure 4: A Comparison of In-depth Temperature Profiles in air and Nitrogen for External Radiation of $2 \mathrm{~W} / \mathrm{cm}^{2}$.

American Institute of Aeronautics and Astronautics 


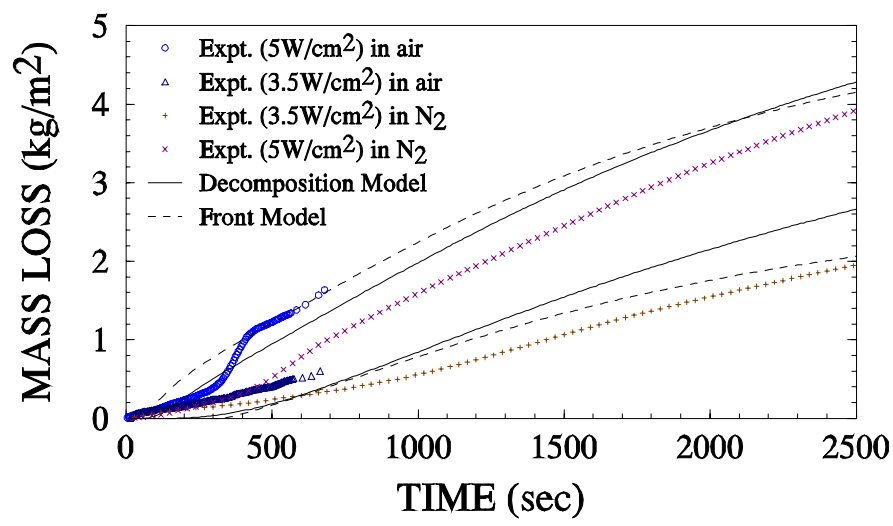

Figure 5: Sample mass loss per unit area for experiments in air and nitrogen atmospheres. Predictions from the two models are also shown.

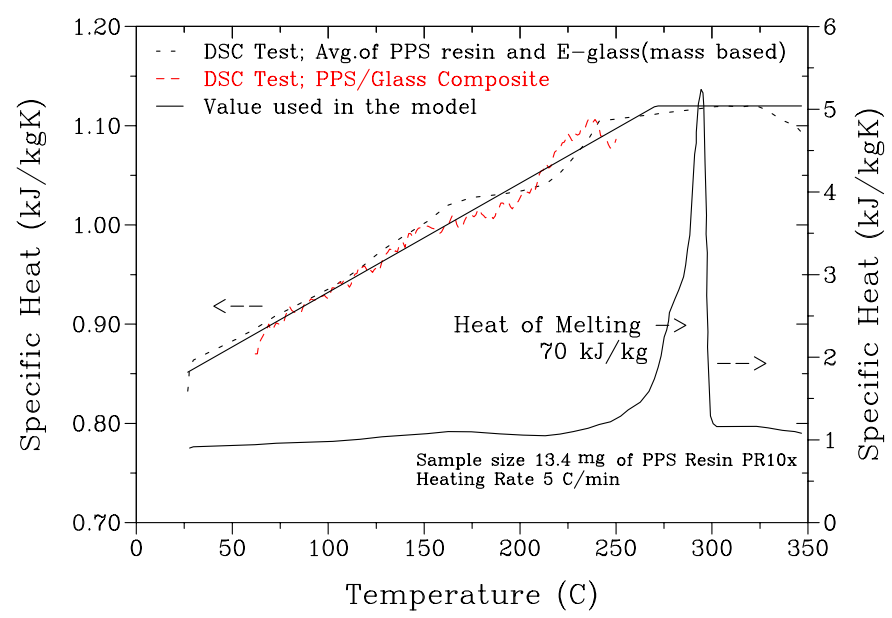

Figure 7: Differential Scanning Calorimetry (DSC) results for PPS -fiberglass composite. The heat of melting is also shown.

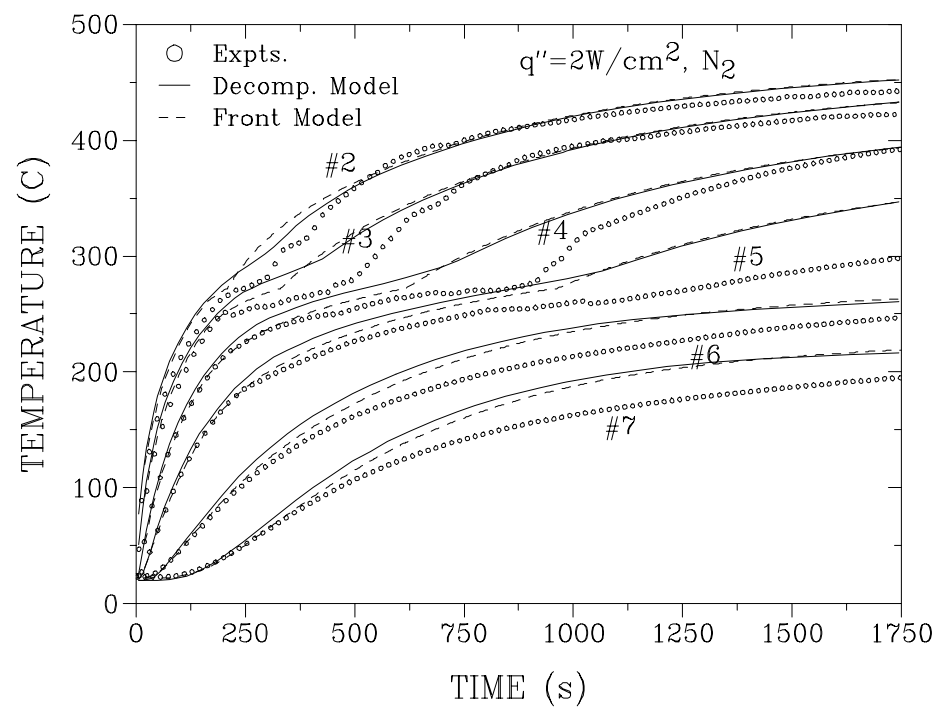

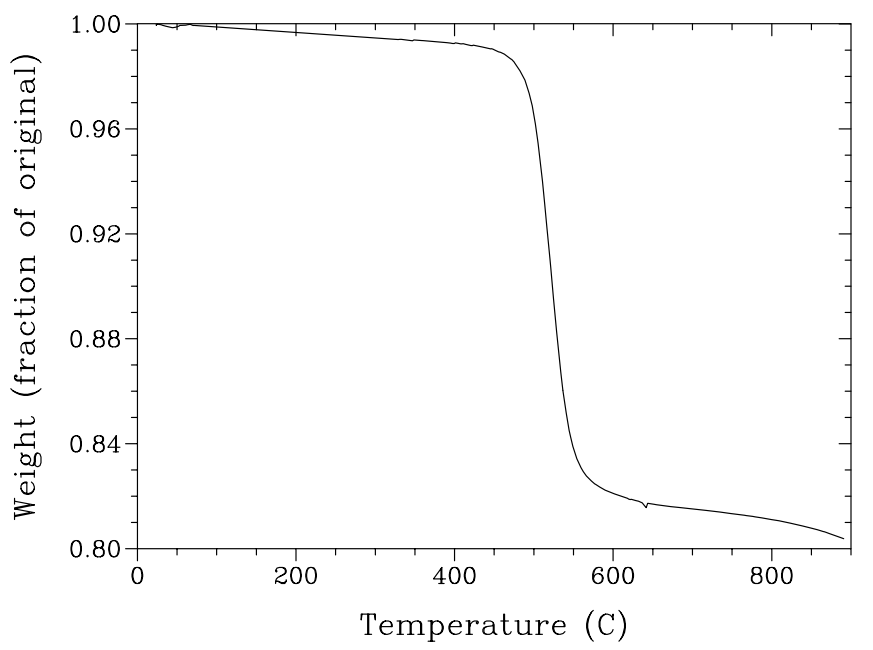

Figure 6: Thermogravimetric analysis (TGA) of PPS-glass fiber composite sample $(34 \mathrm{mg})$. Fractional weight loss vs.

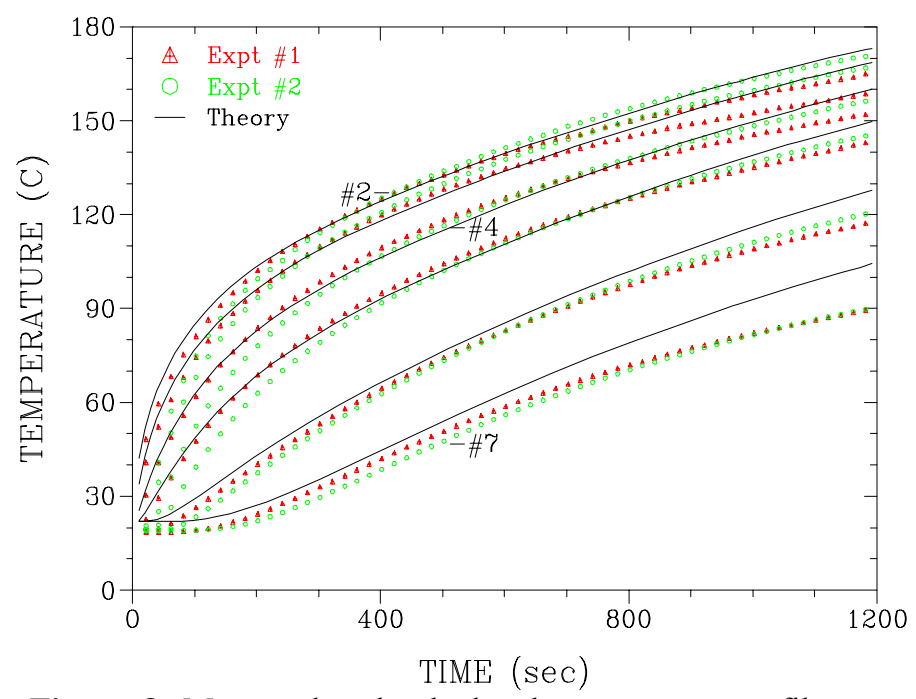

Figure 8: Measured and calculated temperature profiles as a function of time in nitrogen atmosphere for an external heat flux of $0.6 \mathrm{~W} / \mathrm{cm}^{2}$.

Figure 9: Measured and calculated in-depth temperature profiles in nitrogen atmosphere for an external heat flux of $2 \mathrm{~W} / \mathrm{cm}^{2}$. 

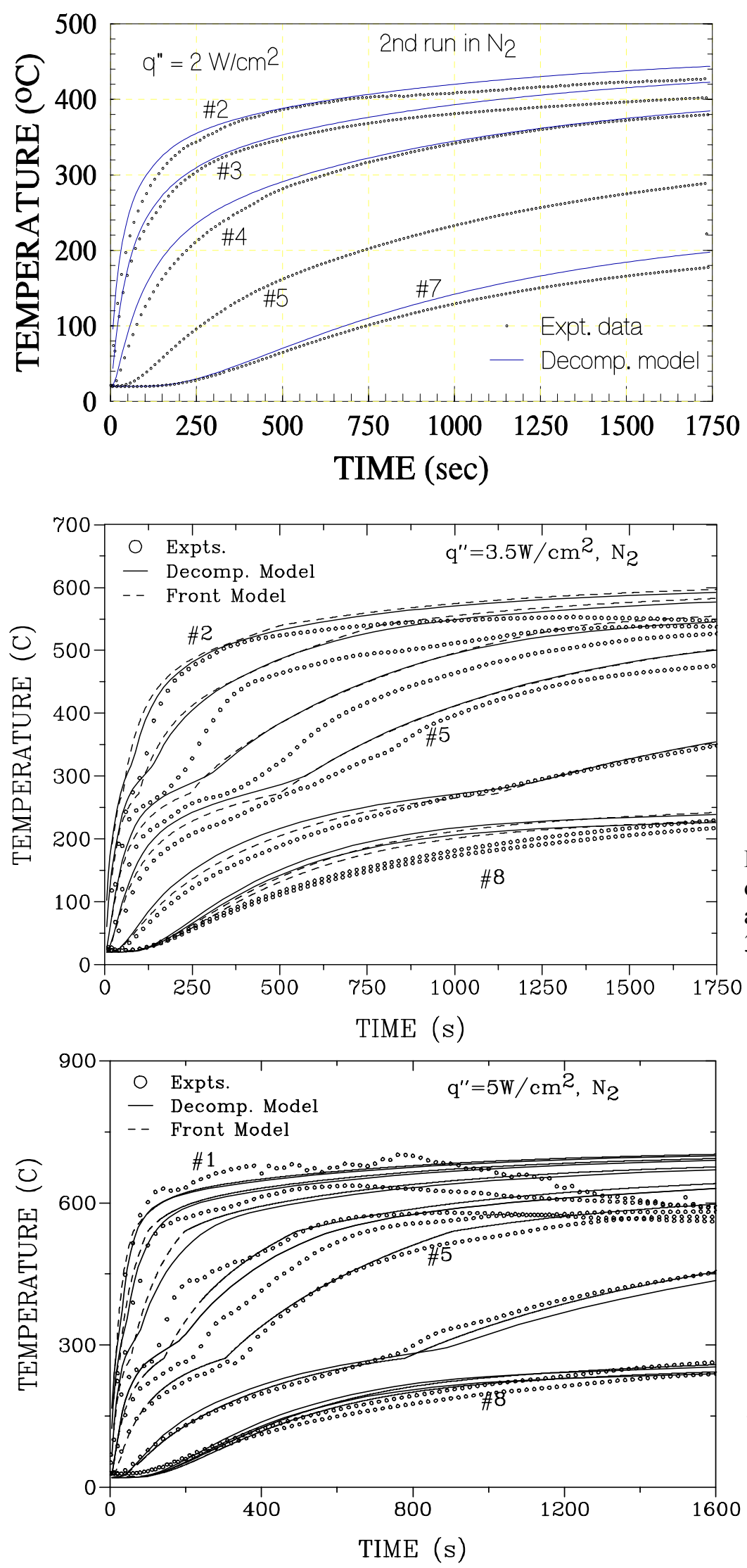

10
Figure 10: In-depth temperature profiles for the sample exposed to $2 \mathrm{~W} / \mathrm{cm}^{2}$ for the second time in nitrogen.
Figure 11: Measured and calculated indepth temperature profiles in nitrogen atmosphere for an external heat flux of $3.5 \mathrm{~W} / \mathrm{cm}^{2}$.
Figure 12: Measured and calculated in-depth temperature profiles in nitrogen atmosphere for an external heat flux of $5 \mathrm{~W} / \mathrm{cm}^{2}$.

American Institute of Aeronautics and Astronautics 